\title{
Acquired Resistance against the Growth of Yoshida Sarcoma Cells in Donryu Rats*
}

\author{
By \\ Haruo Sato, Hiroshi Satoh** and Keiji Fujii \\ From Cancer Research Laboratory, the Research Institute for \\ Tuberculosis, Leprosy and Cancer, Tohoku University, Sendai \\ and the Medical Institute of Sasaki Foundation, Tokyo**
}

(Received for publication, November 25, 1963)

\begin{abstract}
The resistance phenomenon of the hosts against the tumor growth was investigated by using Yoshida sarcoma and Donryu rats. The animals were treated in various ways such as by giving heterograft (transplantation of mouse tumors), injection of cell suspension of various organs, injection of B.C.G., or administration of trypan-blue, typhoid-paratyphoid vaceine, zymosan or india ink, prior to transplantation of Yoshida sarcoma. The acquired resistance was clearly demonstrated especially when small number of tumor cells were inoculated.

Heterografting was the most effective to induce the resistance of the host against the tumor growth, while the resistance was moderately induced by injection of B.C.G. or typhoid-paratyphoid vaccine.

Based on the data obtained, correlation between the resistance of the host against tumor growth and the role of the reticulo-endothelial system was discussed.
\end{abstract}

During the past 20 years in the serial transplantation of the Yoshida sarcoma, a lot of strange phenomenon in the tumor growth have been experienced. One of those, the "unusual" procedure, has been noticed in the transplantation records. When the tumor cells of Yoshida sarcoma were transplanted intraperitoneally in the rats, the animals usually died of tumor within 10 or 15 days after transplantation. There were some cases observed, however, in which the tumor bearing hosts survived for a longer time than 1 or 2 months. In some of these animals, the tumors disappeared once, and appeared again, or the tumor began to grow in the different site from the initially transplanted place, or the tumor inoculated intraperitoneally grew in a solid form at the abdominal wall or in the retroperitoneal tissue. These procedures are summarized as "unusual" procedure of the tumor growth". If the tumor cells were obtained from the tumor tissues of the

佐藤春郎, 佐藤 博, 藤井敬二

* This paper was read at the 3rd General Meeting of the Japan Society of the Reticuloendothelial System, May 31, 1963 in Nagoya. 
hosts which showed this "unusual" procedure, and these cells were transplanted into the new hosts, there would be observed the same usual tumor growth in the recipient animals as seen before. These abnormal processes in the tumor growth are assumed not to be attributed to any essential changes in the tumor cells, but to be correlated with some unknown factors which might be existing in the tumor bearing hosts.

Since the Donryu rats have been used for the transplantation of Yoshida sarcoma, the transplantability of the tumor became so uniform, and the number of cases with "unusual procedure" has been decreasing markedly. Now we can hardly observe any non-take or unusual procedure if the tumors were inoculated into the Donryu rats.

Thus, a series of experiments has been carried out to study on this "unknown" factor(s) of the hosts, which might be controlling the growth of tumors. For this purpose, the materials of the Yoshida sarcoma and the Donryu rats, seemed to be adequate in this kind of experiments. Thus for example, the Donryu rats were pretreated in various ways, such as heterografts ${ }^{2,3}$, injection of the cell suspension, B.C.G. injection ${ }^{4,5}$, administration of trypan blue, typhoidparatyphoid vaccine, zymosan, or india ink $\left.{ }^{6}, 7\right)$.

There were observed the marked resistance acquired in the host animals, in which the tumor cells should have grown markedly, and which should have been dead with tumors. Thus, many of those animals survived longer than usual, and the growth percentage in the tumor growth ${ }^{8)}$ became markedly low, and the survival rate increased. This occurred frequently when the small numbers of tumor cells were transplanted. The animals which survived through the first challenge of tumor cells, used to acquire the resistance against the further challenge with large number of tumor cells. In this paper, the results obtained in the series of experiments along the line of the tumor-host relationship, are dealt with, together some considerations about the correlation between the reticulo-endothelial system and the resistance of a host to the growth of tumor.

\section{MATERIALS AND METHODS}

\section{Animals}

Donryu rats, in which the high transplantability of the Yoshida sarcoma ${ }^{9}$ has been known, were used in this series of experiments. All were kept on a standard pellet diet, together with drinking water, ad libitum. The animals of both sexes, weighing 70 to $100 \mathrm{gm}$ were used, and they were housed in a big cage by each experimental group of 10 or 20 rats according to sex and weight.

\section{Tumors}

Six kinds of tumor cells were used. These were three strains of $\mathrm{C} 3 \mathrm{H}$ mouse ascites hepatomas (MH134, MH129F, MH129P), one dd mouse ascitic leukemia 
(SN36), one ascites tumor of $\mathrm{C} 3 \mathrm{H}$ mammary cancer (FM3A) and one rat ascites tumor (Yoshida sarcoma). All of these tumors are being maintained in the ascites form by serial intraperitoneal transplantation in this laboratory.

\section{Transplantation of tumor cells}

The tumor cells for transplantation were obtained from the peritoneal cavity of the animals 4 or 5 days after transplantation. In this state, ascitic fluids were usually showing the "pure culture state" of tumor cells. In order to transplant with small numbers of tumor cells, the ascites was diluted with physiologic saline and necessary numbers of them were counted by using the Thoma-Zeiss counting apparatus, and inoculated into the peritoneal cavity of the rats respectively.

\section{Preparation and methods of pretreatment}

a) Heterotransplantation

The ascites tumors of the mouse were used for heterotransplantation. Each of different tumors suspended in physiologic saline, was transplanted into the peritoneal cavity of the rats, and the inoculum contained about $10^{6}$ to $10^{7}$ of tumor cells. These heterografts used to show the spontaneous regression. Small numbers of Yoshida sarcoma cells were inoculated intraperitoneally at various intervals (19-107 days) after heterotransplantation. The smears of the ascites were made in the same manner as the blood smears, and were stained with Wright-Giemsa staining.

b) Cell suspension of various organs

Rats were sacrificed by cervical dislocation. The organs such as the liver, kidney and spleen were removed, and washed out with physiologic saline. These materials were cut into pieces with scissors and pushed through the mesh stainlesssteel screen, then the mash was suspended in physiologic saline. Each cell suspension contains about $35 \%$ of the liver cells, $25 \%$ of the kidney cells, and $10 \%$ of the spleen cells, respectively. Each of these cell suspensions was intraperitoneally inoculated in the peritoneal cavity of the rats respectively, and 10 days later, small numbers of Yoshida sarcoma cells were transplanted.

c) Treatment of B.C.G.

The B.C.G. vaccine produced and supported by B.C.G. Laboratory of our Institute was injected into the tail vein of the rats. The tumor cells (Yoshida sarcoma cells) were inoculated intraperitoneally on the 10th day after B.C.G. treatment.

d) Treatment of trypan blue

One percent of trypan blue solution was prepared aseptically and was injected intraperitoneally. The dose given was $0.5 \mathrm{ml}$ per $100 \mathrm{gm}$ of body weight. The rats were transplanted intraperitoneally with small numbers of Yoshida sar- 
coma cells on the 4th day after treatment of trypan blue.

e) Treatment of typhoid-paratyphoid vaccine

The typhoid-paratyphoid vaccine produced by Kitazato Institute, was used. One $\mathrm{ml}$ of typhoid-paratyphoid vaccine per $100 \mathrm{gm}$ of body weight was inoculated intraperitoneally on the 4 th day prior to inoculate small numbers of Yoshida sarcoma cells.

f) Treatment of zymosan

Zymosan produced according to the method of Pillemer was obtained from Tuberculin Laboratory of our Institute. Single dose of $20 \mathrm{mg}$ per $100 \mathrm{gm}$ body weight was injected into the peritoneal cavity on the 4th day before inoculation of Yoshida sarcoma cells. The numbers of cells inoculated were $10^{3}$ and $10^{6}$, respectively.

g) Treatment of india ink

Inida ink made by Günther Wagner, Hannover, was used mainly in this study and in some groups by Pilot Ink Co., Japan. The ink was aseptically diluted in $10 \%$ of physiologic saline. One $\mathrm{ml}$ of ink per $100 \mathrm{gm}$ of body weight was injected intraperitoneally and the rats were inoculated with small numbers of Yoshida sarcoma cells 4 days after the injection.

\section{Examination of the animals after tumor transplantation}

The ascites of the animals were examined on the $2 \mathrm{nd}$, 5th, 10th, 15th and 20th day after transplantation, respectively, and the growth percentage of ascites tumor was estimated, together with survival days of the animals.

\section{RESULTS}

I) Acquired resistance against the growth of Yoshida sarcoma cells following the heterograft in Donryu rat: It was attempted to demonstrate the role of the host resistance against the growth of the inoculated small numbers of Yoshida sarcoma cells following inoculation of mouse ascites tumors. The animals were pretreated with each of different mouse tumors, which were MH134, MH129F, MH129P, FM3A and SN36 respectively. The mouse tumor cells grew in the abdominal cavity of rats for a while, but because of heterografting, soon regressed. Thereafter, $90 \%$ of rats were survived. Following the regression of mouse tumors, the survived animals were given an intraperitoneal challenge of small numbers of Yoshida sarcoma cells. The intervals between inoculation of mouse tumor and Yoshida sarcoma were 19 to 107 days. The non-treated control rats also received the same cell doses (Fig. 1). All of animals in the non-treated control groups died with tumor, and marked tumor growth was observed. Among the experimental groups, given with various numbers of Yoshida sarcoma cells, the most prominent effect was observed in the group inoculated with $10^{3}$ cells, following the heterograft. The results are shown in Table I and Fig. 2, where the high survival rate is marked 


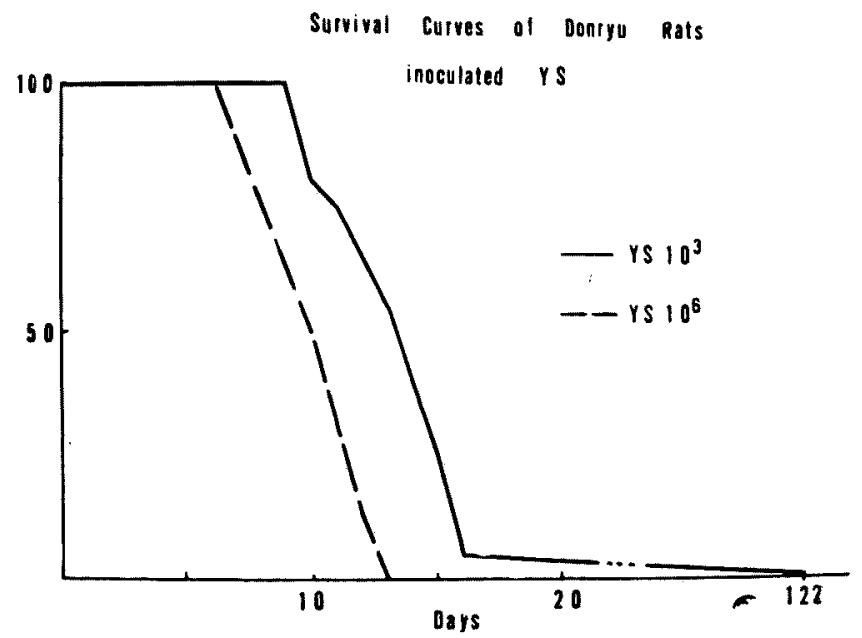

Fig. 1. Survival curves in Donryu rats inoculated with small numbers $\left(10^{9} \& 10^{6}\right)$ of Yoshida sarcoma cells (control).

TABle I. Tumor Death and Mean Survival Days in Donryu

Rats Inoculated with Yoshida Sarcoma Cells following the Heterografts

\begin{tabular}{l|l|l|l|l}
\hline & \multicolumn{4}{|c}{ No. of YS cells } \\
\cline { 2 - 5 } & $10^{3}$ & $10^{4}$ & $10^{5}$ & $10^{6}$ \\
\hline No. of rats & 89 & 90 & 67 & 85 \\
No.of tumor death & 14 & 29 & 33 & 53 \\
\% & 15.7 & 32.2 & 49.3 & 62.4 \\
Mean survival days & 38.8 & 21.6 & 18.6 & 10.1
\end{tabular}

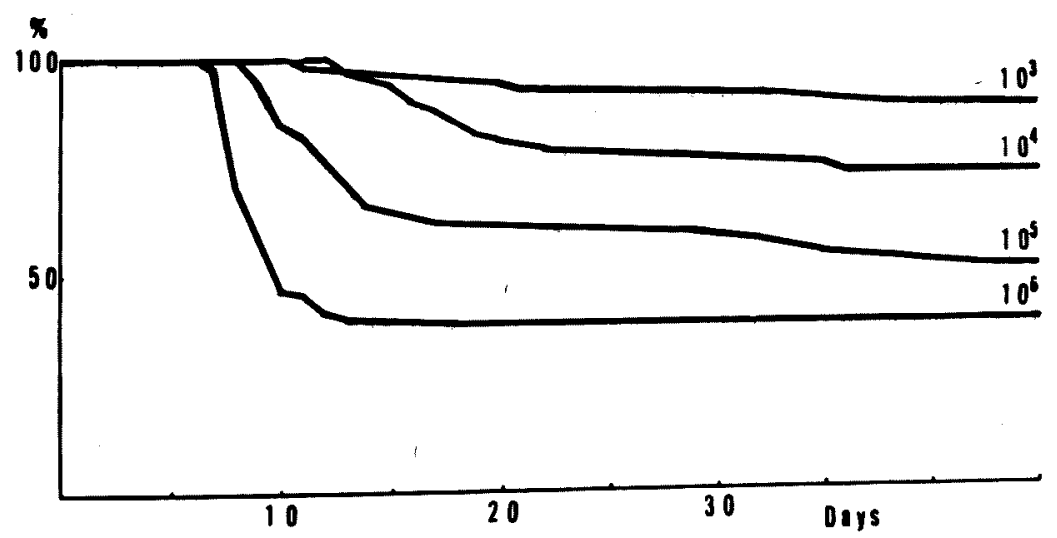

Fig. 2. Survival curves in Donryu rats inoculated with various numbers of Yoshida sarcoma cells following the heterografts. 
in the group of recipients of small numbers of Yoshida sarcoma cells following heterograft, and mean survival days of those rats were longer than the control group. Differences among pretreated mouse tumors were demonstrable for SN36 group and MH129P group. The former is independent on cell doses of Yoshida sarcoma following pretreatment of SN36. The survival rate for $10^{3}$ group and $10^{6}$ group pretreated with SN36 were $90 \%$ and $84.2 \%$ respectively, and control group was $0 \%$. But in the latter group pretreated with MH129P the inoculated cell doses of Yoshida sarcoma is concerned. The survival rate was lower in this group than in the former group. It was $50.0 \%$ in the rats inoculated with $10^{3}$ cells and $5.8 \%$ in the $10^{6}$ group. The results suggest there might be some differences among the materials used for pretreatments. As indicated in Table II, the resistant rats against Yoshida sarcoma following he-

Table II. Survival Rate in Donryu Rats Inoculated with Various Numbers of Yoshida Sarcoma Cells following the Heterografts

\begin{tabular}{l|r|r|r|r|r|r}
\hline \multirow{2}{*}{ Mode of transplant. } & \multicolumn{5}{|c}{ No. of tumor cells inoculated } \\
\cline { 2 - 7 } & $10^{3}$ & $10^{4}$ & $10^{5}$ & $10^{8}$ & $10^{7}$ & $>10^{7}$ \\
\hline Hetero-transplant. & - & - & - & $200 / 218$ & $88 / 99$ & $44 / 46$ \\
& & & & $(91.7)$ & $(88.9)$ & $(95.8)$ \\
Homo-transplant. following & $75 / 89$ & $61 / 90$ & $34 / 67$ & $32 / 85$ & - & - \\
$\quad$ hetero-transplant. & $(84.3)$ & $(67.8)$ & $(50.7)$ & $(37.6)$ & & \\
Homo-transplant. following & - & - & - & $24 / 33$ & $134 / 153$ & - \\
hetero-homo-transplant. & & & & $(72.7)$ & $(87.6)$ & \\
Homo-transplant. following & - & - & - & - & $79 / 80$ & - \\
hetero-homo-homo-transplant. & & & & & $(98.9)$ &
\end{tabular}

terograft showed the inhibition of the growth in the repeated challenge of large number of Yoshida sarcoma cells. The survival rate was an extremely high value; $72.7 \%$ of the rats in the $10^{6}$ inoculated group did not die of tumor, while in the $10^{7}$ inoculated group, $87.6 \%$ survived. After this, similar high resistance was also obtained. The rats which acquired resistance against the growth of small numbers of Yoshida sarcoma cells were no longer killed by repeated inoculation of large cell doses of Yoshida sarcoma. These results indicate that the resistance of the hosts against the growth of Yoshida sarcoma was acquired and increased by inoculation of incompatible mouse tumor cells. It is clear from these data that the resistance against Yoshida sarcoma in the rats had been gradually elevated, and was fully reflected by the high survival percentage, the disappearance of tumor cells in the ascites and the decrease in the growth percentage of tumors.

II) Acquired resistance against the growth of Yoshida sarcoma cells following inoculation of the cell suspension from various organs: The preparation of cell suspension from organs was performed as already mentioned above. The 
normal healthy rats were intraperitoneally inoculated with the cell suspension from different organs such as the liver, kidney and spleen, respectively. In this experiment, the animals were divided into A, B and C groups. The A-group animals were intraperitoneally inoculated with the cell suspension of the organs from the cortisone treated resistant rats. These rats were treated previously by repeated inoculations of Yoshida sarcoma following spontaneous regression of the intraperitoneally transplanted rat ascites hepatoma. These rats were intramuscularly administered with cortisone acetate at a dose of $10 \mathrm{mg} / 100 \mathrm{gm}$ body weight/day for 7 days and inoculated with much cell doses of Yoshida sarcoma on the 4th day of administration of cortisone (group of cortisone treated organ). The B-group was intraperitoneally inoculated with the cell suspension of the organs obtained from the resistant rats as the same above $\mathbf{A}$. The difference between A and B was that B group was intravenously administered with $10 \%$ Pilot ink at a dose level of $1 \mathrm{ml} / 100 \mathrm{gm}$ body weight instead of cortisone acetate (group of carbon treated organ). The C-group was intraperitoneally inoculated with the cell suspension of the organs from isologous healthy rats (group of nontreated organ). Ten days after inoculation of the cell suspension, the Yoshida sarcoma cells were then intraperitoneally transplanted into the pretreated rats at the cell dose level of $10^{4}$. The comparison between organs and pretreatments yielded the data shown in Table III. On the pretreatments, it can be seen in this

TABLE III. Survival in Donryu Rats Transplanted with Yoshida Sarcoma $\left(10^{4} \text { cells }\right)^{*}$ following Inoculation of the Cell

Suspension of Various Organs

\begin{tabular}{l|c|c|c|r|r}
\hline \multirow{2}{*}{ Pretreated } & \multicolumn{5}{|c}{ Suspension of } \\
\cline { 2 - 6 } & Liver cells & $\begin{array}{c}\text { Spleen } \\
\text { cells }\end{array}$ & $\begin{array}{r}\text { Kidney } \\
\text { cells }\end{array}$ & \multicolumn{2}{|c}{ Total } \\
\hline Cortisone & $1 / 10$ & $7 / 9$ & $1 / 10$ & $9 / 29$ & $(31.0)$ \\
Carbon & $7 / 10$ & $10 / 10$ & $9 / 9$ & $26 / 29$ & $(89.7)$ \\
None & $5 / 5$ & $4 / 5$ & $5 / 5$ & $14 / 15$ & $(93.4)$ \\
Total & $13 / 25$ & $21 / 24$ & $15 / 24$ & $49 / 73$ & \\
& $(52.0)$ & $(87.5)$ & $(62.5)$ & $(67.1)$
\end{tabular}

* After 10 days, Survived/Valid, ( ): \%

table that the survival rate of the animals was $93.4 \%$ in the group of nontreated organ (C), $89.7 \%$ in the group of carbon treated organ (B) and $31.0 \%$ in the group of cortisone treated organ (A) respectively. On the other hand, the survival rate was $87.5 \%$ in the group of spleen cells, $62.5 \%$ in the group of kidney cells and $52.0 \%$ in the group of liver cells, respectively. The acquired resistance against Yoshida sarcoma seemed to be different, depending on the cell suspensions by each organ used. An extremely high survival rate were shown by the 


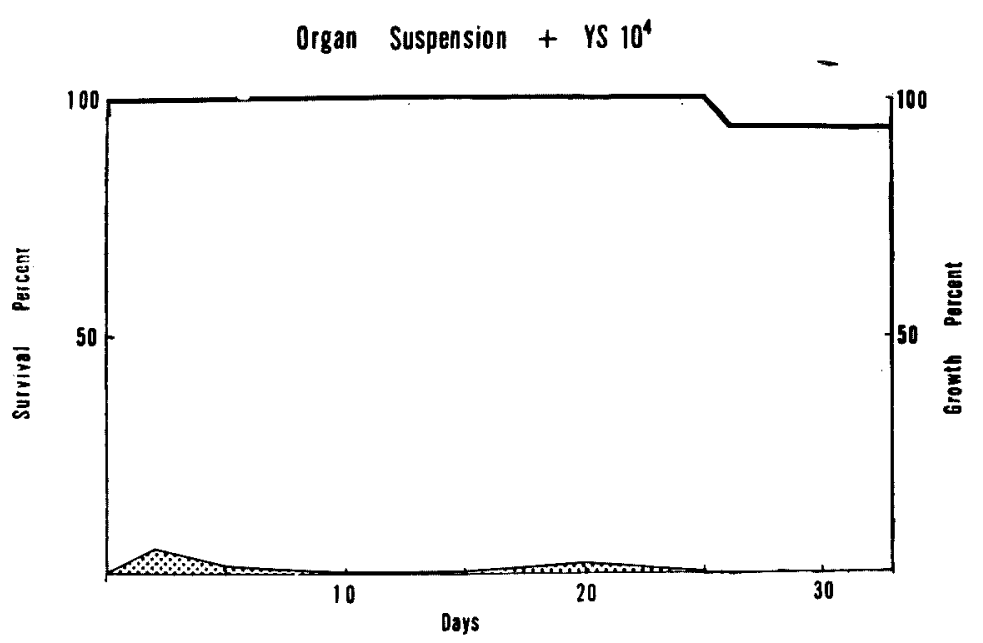

Fig. 3. Survival curve and growth percentage of tumor in Donryu rats transplanted with Yoshida sarcoma following the cell suspension of various organs (non-treated group).

group of the spleen cells. The Fig. 3 shows the survival curve and the growth percentage in the Yoshida sarcoma rats of the group C. The survival rate in the animals transplanted with $10^{4}$ of Yoshida sarcoma cells were markedly high value in the pretreated groups as compared to $0 \%$ in the control group. It seems not exaggerated to consider that the hosts acquired the resistance against the growth of Yoshida sarcoma cells following inoculation of the cell suspension from those organs. There seems to be some differences among the grade of resistance acquired by each cell suspension prepared.

III) Acquired resistance against the growth of Yoshida sarcoma cells following B.C.G. treatment.

Viable B.C.G. vaccine was intravenously inoculated into the tail vein of rats at a dose level of $3 \mathrm{mg}$ per rat. Ten days later, each dose of $10^{3}, 10^{4}, 10^{5}$ and $10^{6}$ cells of Yoshida sarcoma was then intraperitoneally inoculated into the pretreated rats. Table IV shows that the survival of rats was increased to $40 \%$ at a dose level of $10^{3}$ cells and to $5 \%$ at a dose level of $10^{6}$ cells in comparison with the control groups. And the mean survival days were 16.2 days in the group of rats inoculated with $10^{3}$ cells, 14.6 days in $10^{4}$ group, 10.8 days in $10^{5}$ group and 8.4 days in $10^{6}$ group, respectively. The B.C.G. treated groups showed a consistantly longer survival days in comparison with the control groups.

Generally speaking, the difference of host resistance is highly significant for all inoculum doses, and the resistance against the growth of Yoshida sarcoma was acquired through the pretreatment of B.C.G. inoculation. But it was not so strong as in those in the experiments of I) and II) mentioned above. 
Table IV. Survival Percentage of Donryu Rats Transplanted with Yoshida Sarcoma following the B.C.G. Treatment

\begin{tabular}{c|cc|c|c}
\hline Exp. Group & \multicolumn{2}{|c|}{ No. of Cells } & Survival/Total & Percent \\
\hline BCG YS & YS & $10^{3}$ & $8 / 20$ & 40 \\
" & " & $10^{4}$ & $4 / 19$ & 21.1 \\
" & " & $10^{5}$ & $1 / 18$ & 5.5 \\
" & " & $10^{6}$ & $1 / 20$ & 5.0
\end{tabular}

IV) Relationship between tumor growth and reticuloendothelial function in the rats:

Trypan blue, typhoid-paratyphoid vaccine, zymosan and india ink were used in these experiments.

(a) Pretreatment with trypan blue

It was of interest to see whether the resistant mechanism against the growth of tumor could be altered in the hosts pretreated with trypan blue. As indicated in Fig. 4, the rats treated with trypan blue exhibited no change in comparison with

Homograft lollowing Trypan blus

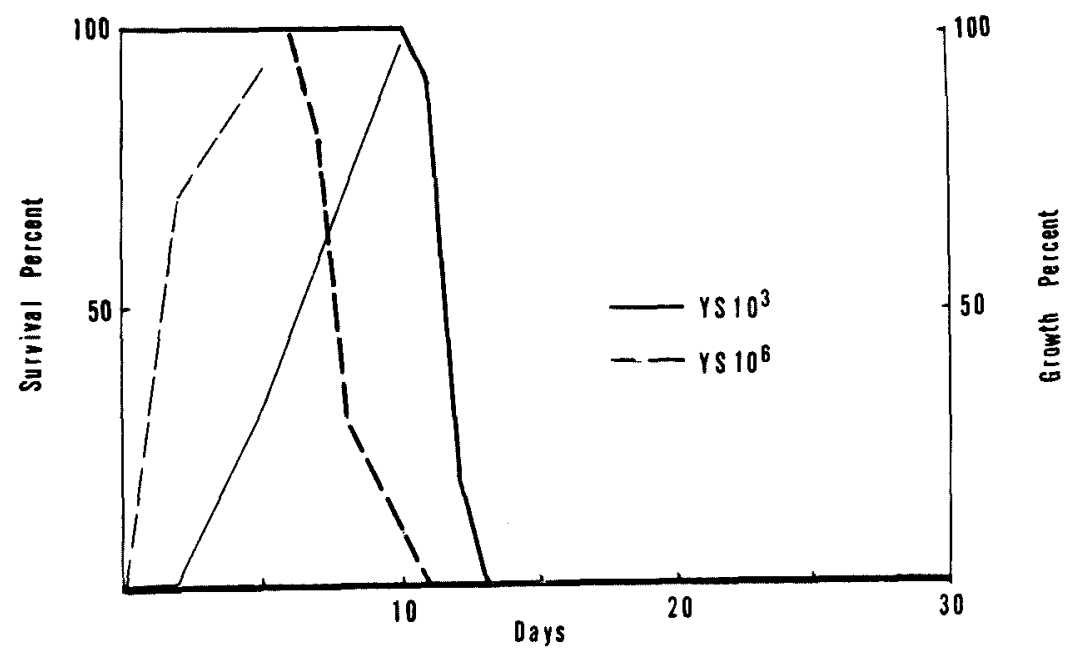

Fig. 4. Survival curves and growth percentage of tumor in Donryu rats transplanted with Yoshida sarcoma following the pretreatment of trypan blue.

the control group. Survival days were 11 to 13 days in the $10^{3}$ cells group after inoculation and 7 to 11 days in the $10^{6}$ group. The autopsy findings of the rats in these groups showed no difference in comparison with the control group. The growth percentage of tumor cells in the ascites of the $10^{6}$ group was $70.0 \%$ on the 
2nd day, and $92.5 \%$ on the 5th day after inoculation, while that in the $10^{3}$ group was $0.7 \%$ on the 2 nd day, $32.5 \%$ on the 5 th day, and $97.5 \%$ on the 10 th day. It may be reasonable to assume that the effects on the resistance mechanism were exhibited of the host in the early stage of tumor growth.

(b) Pretreatment with typhoid-paratyphoid vaccine

The results in the group pretreated with typhoid-paratyphoid vaccine are summarized as seen in Fig. 5; all animals in the $10^{6}$ cells group died of tumor 8 to

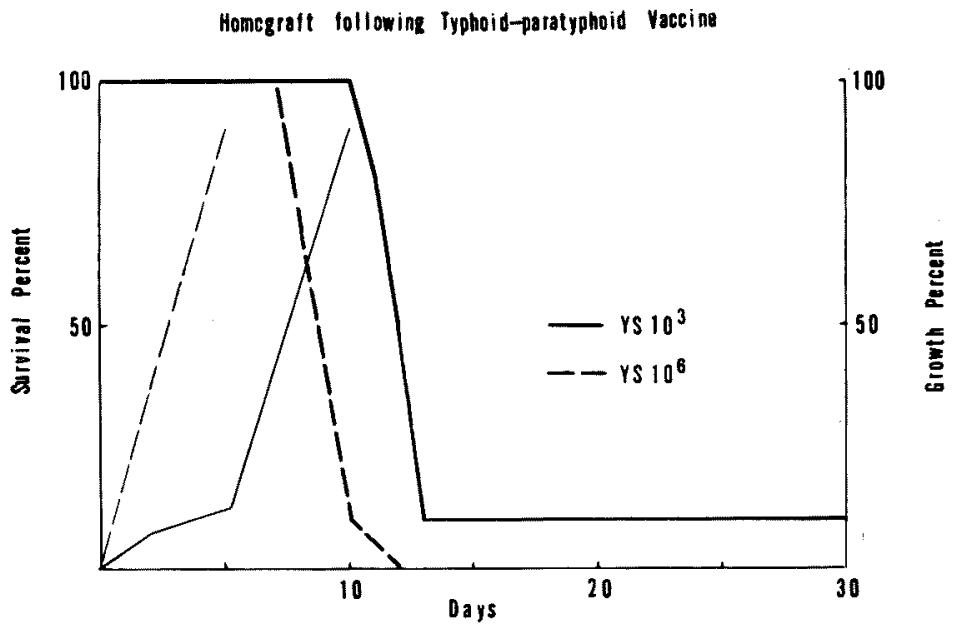

Fig. 5. Survival curves and growth percentage of tumor in Donryu rats transplanted with Yoshida sarcoma following the pretreatment of typhoid. paratyphoid vaccine.

12 days after inoculation, and the growth percentage was $37.5 \%$ on the 2 nd day and $90 \%$ on the 5 th day; in the $10^{3}$ cells group, the survival rate was $10 \%(1 / 10)$, and they died of tumor 11 to 13 days after inoculation. It may be considered that the doses used were not efficient to induce a certain resistance against Yoshida sarcoma.

(c) Pretreatment with zymosan

Fig. 6 shows the survival curves and the growth curves in the animals of zymosan treated group. Although the $10^{6}$ group indicates the same result as seen in the previous two cases, while the $10^{3}$ group shows a certain host resistance against Yoshida sarcoma. The growth percentage was low for a while in the group transplanted with such small numbers of Yoshida sarcoma cells, but in later days it usually increased moderately in comparison with the earlier days. It may be thought that the normal challenge dose $\left(10^{6}\right)$ could not reveal the host resistance against the growth of Yoshida sarcoma, but the small number of cell 


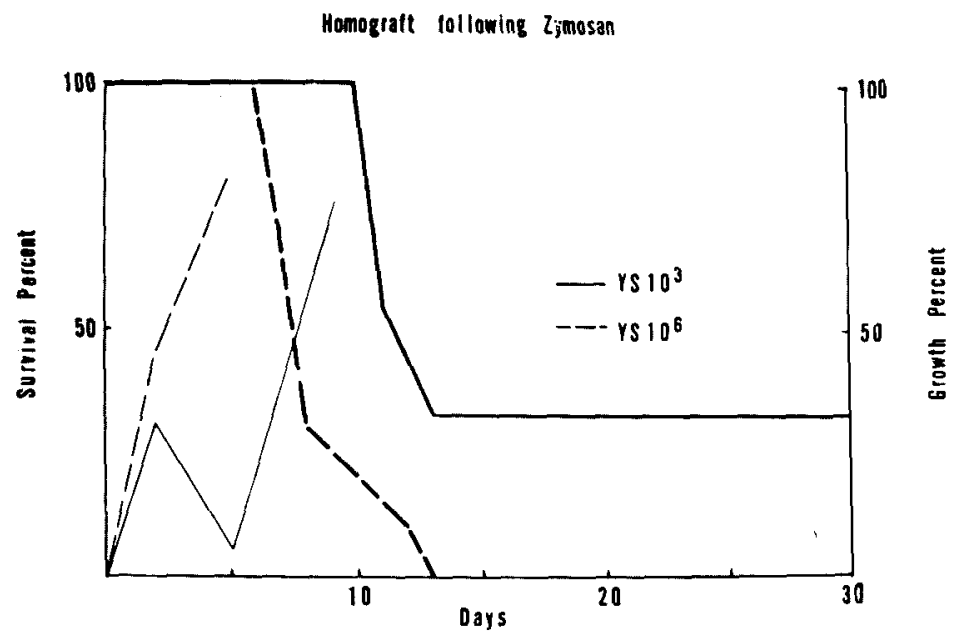

Fig. 6. Survival curves and growth percentage of tumor in Donryu rats transplanted with Yoshida sarcoma following the pretreatment of zymosan.

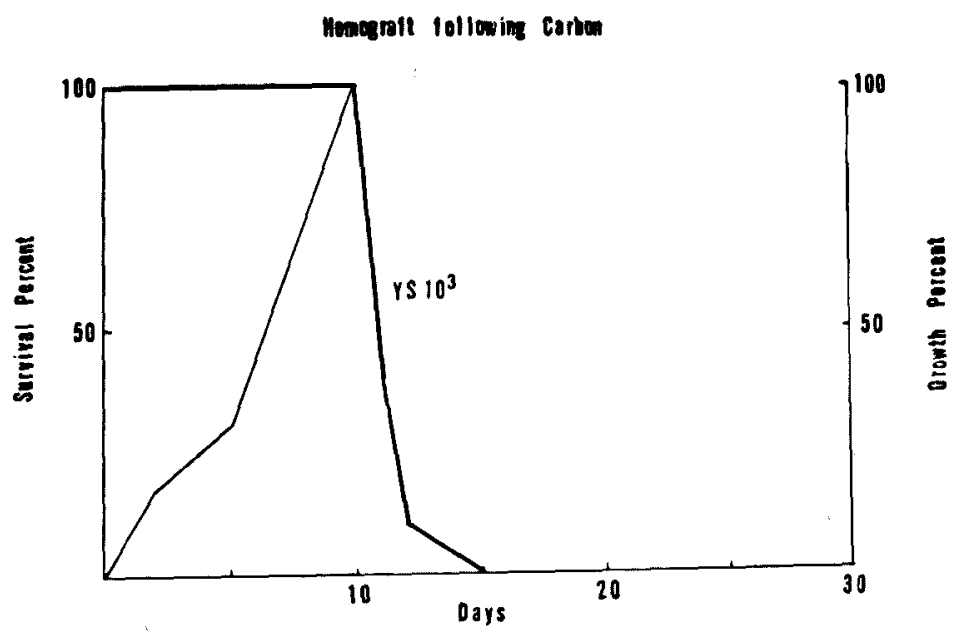

Fig. 7. Survival curve and growth percentage of tumor in Donryu rats transplanted with Yoshida sarcoma following the pretreatment of carbon.

dose could reveal it clear.

(d) Pretreatment of india ink

As shown in Fig. 7, there were no elongation in the survival and decrease in growth percentage in this group of animals.

V) Growth of Yoshida sarcoma in the rats with acquired resistance through the homografts and heterografts: 
The rats with acquired resistance were obtained as follows:

(1) Rats which showed the spontaneous regression after inoculation of rat ascites hepatoma, and failed to take in the transplantation of Yoshida sarcoma. (resistance through the homograft)

(2) Rats which had no take of Yoshida sarcoma following inoculation of mouse ascities tumors (resistance through the heterograft). In this experiment, the rats of the former group were divided into two, and those in the latter were divided into three sub-groups, respectively. The former sub-groups were pretreated as follows:

(1-a) Serial injection of cortisone acetate at a dose of $10 \mathrm{mg}$ per $100 \mathrm{gm}$ of body weight for 7 days.

(1-b) Intraperitoneal injection of $10 \%$ Pilot ink at a dose of $1 \mathrm{ml}$ per $100 \mathrm{gm}$ body weight for 7 days. And the latter sub-groups were pretreated as follows: (2-a) Serial injection of cortisone acetate at a dose of $10 \mathrm{mg}$ per $100 \mathrm{gm}$ body weight for 3 days prior to the inoculation of Yoshida sarcoma.

(2-b) Single injection of $10 \%$ Pilot ink at a dose of $1 \mathrm{ml}$ per $100 \mathrm{gm}$ of body weight in the tail vein prior to the inoculation of Yoshida sarcoma.

(2-c) Single irradiation of $\mathrm{Co}^{60}$ at a dose level of $200 \mathrm{r} / 20 \mathrm{~min} . / \mathrm{rat}$.

The numbers of inoculated Yoshida sarcoma cells were $10^{7}$.

Figs. 8, 9, 10, 11 and 12 show the results of each group.

The resistance against Yoshida sarcoma in the former group was not changed by these pretreatments such as cortisone and india ink. The growth percentage of the tumor indicated very low level. It means that the recipients previously

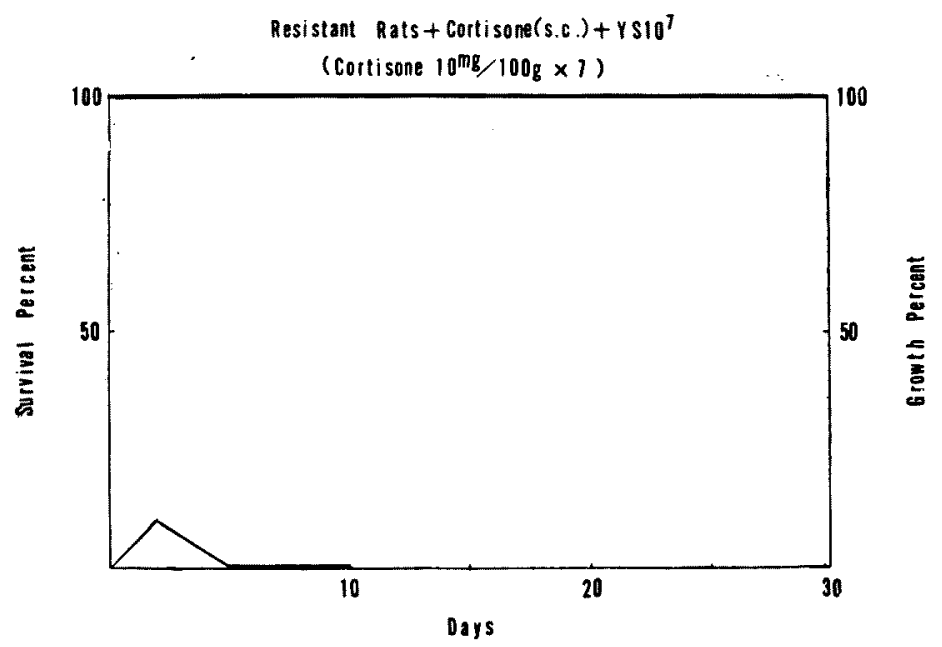

Fig. 8. Survival curve and growth percentage of tumor in the resistant rats injected with cortisone acetate at a dose of $10 \mathrm{mg}$ per $100 \mathrm{gm}$ body weight for 7 days (1-a). 


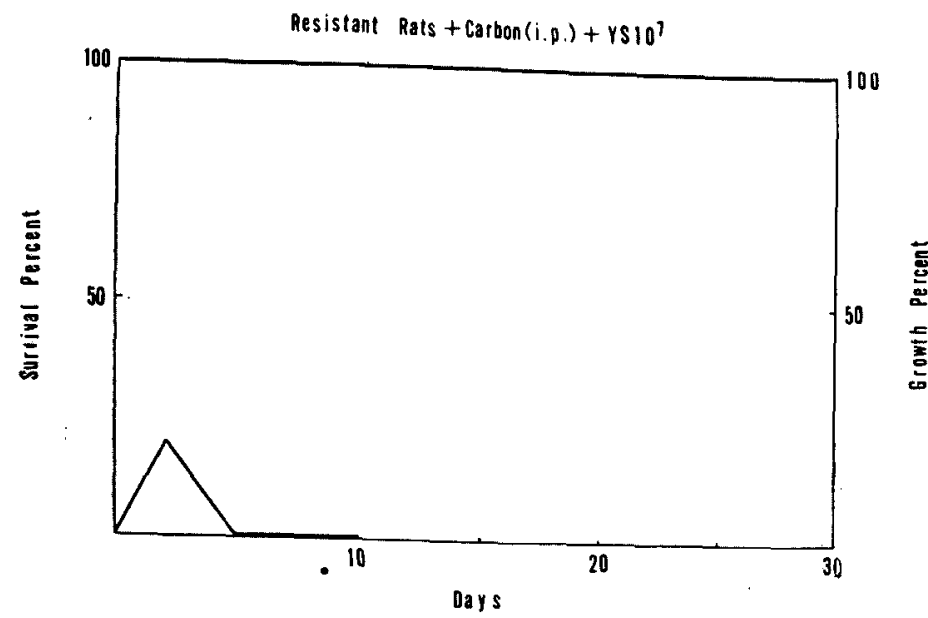

Fig. 9. Survival curve and growth percentage of tumor in the resistant rats injected with $10 \%$ india ink (Pilot ink) at a dose of $1 \mathrm{ml}$ per $100 \mathrm{gm}$ of body weight for 7 days (1-b).

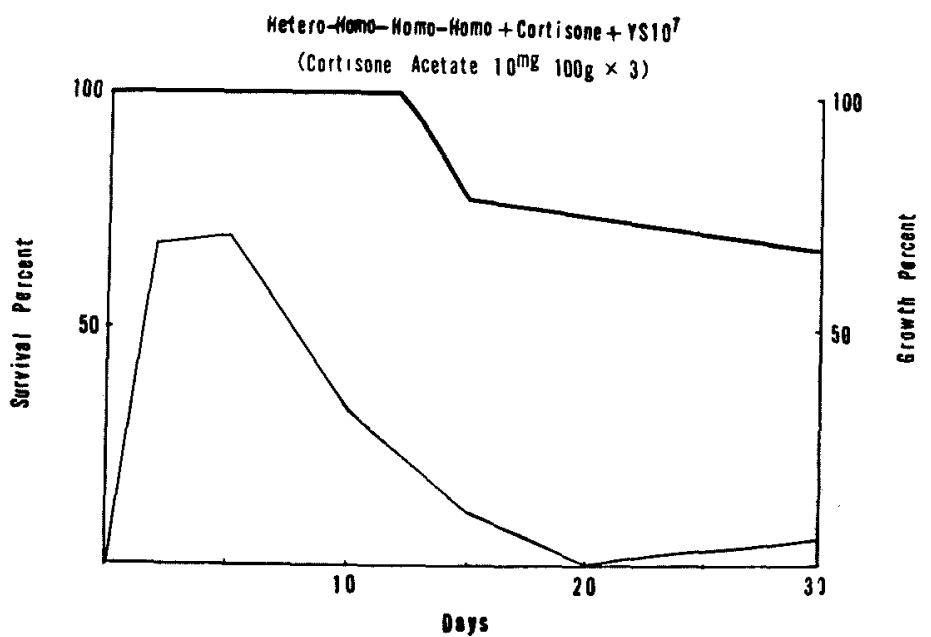

Fig. 10. Survival curve and growth percentage of tumor in the resistant rats injected with cortisone acetate at a dose of $10 \mathrm{mg}$ per $100 \mathrm{gm}$ of body weight for 3 days (2-a).

homografted with rat ascites hepatoma cells had acquired a considerable resistance against the transplantation of Yoshida sarcoma. In the latter, on the other hand, the cortisone pretreated group showed that some animals died with tumor, and the tumors infiltrated macroscopically in the same way as in the control group. It may be considered that the pretreatment of cortisone reduced the resistance 


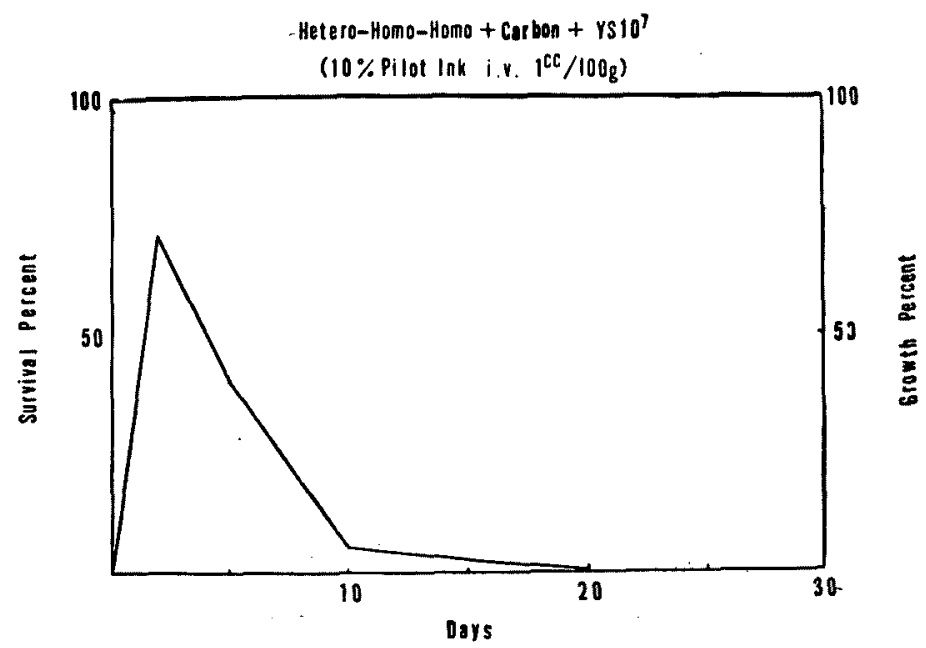

Fig. 11. Survival curve and growth percentage of tumor in the resistant rats injected with $10 \%$ india ink (Pilot ink) at a dose of $1 \mathrm{ml}$ per $100 \mathrm{gm}$ of body weight in the tail vein (2-b).

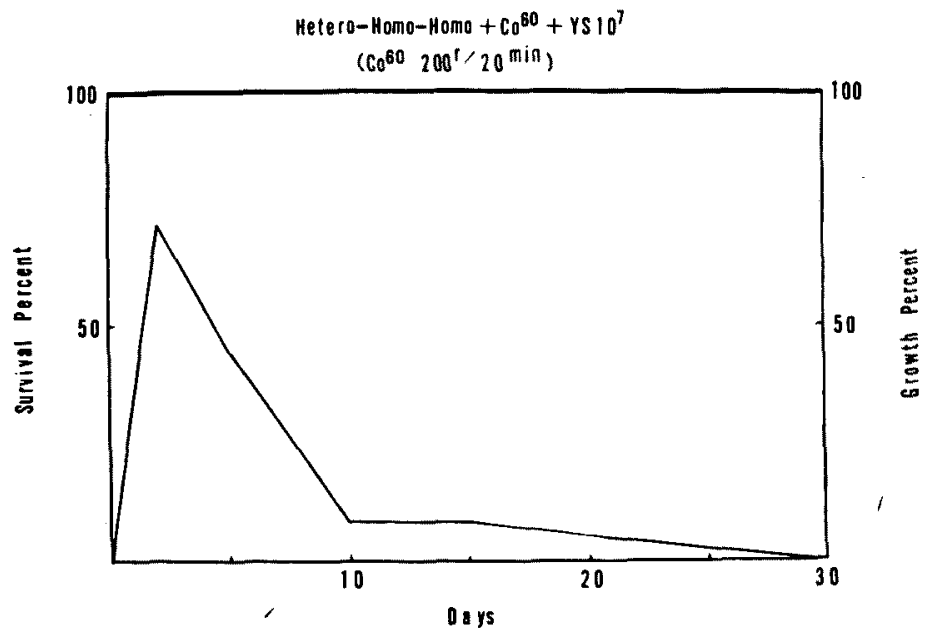

Fig. 12. Survival curve and growth percentage of tumor in the resistant rats irradiated with $\mathrm{Co}^{60}$ at a dose of $200 \mathrm{r} / 200 \mathrm{~min} . / \mathrm{rat} \quad(2-\mathrm{c})$.

for Yoshida sarcoma, but other pretreatments did not induce such a condition. Although the resistance in the hosts of the former group seemed to be more remarkable than in those of the latter, it is enough difficult to explain the difference in these two groups, untill many other factors are uncovered. 
VI) Relative mean values in the leucocyte counts in the ascites following inoculation of the tumors.

Two series in these experiments were examined.

(1) Ascites of the resistant rats, inoculated with Yoshida sarcoma at the dose of $10^{3}$ following B.C.G. treatment, and (2) ascites of the resistant rats, which received the repeated inoculation of Yoshida sarcoma following the regression of MH 129F. The ascites was drown at 2, 5, 10, 15, 20 and 30 days after inoculation. On the slides, two hundred cells except red blood cells were counted at random, and classified. The relative values for the different type of cells in the ascites of the two groups mentioned above are given in Table V and VI.

TABLE V. Mean Relative Values of Leucocyte Counts in Donryu

Rats Inoculated with Yoshida Sarcoma Cells following the B.C.G. Treatment

\begin{tabular}{l|r|r|r|r|r|r}
\hline \multirow{2}{*}{ Cell type } & \multicolumn{3}{|c}{ Days after transplantation } & (YS & $\left.10^{3}\right)$ \\
\cline { 2 - 7 } & 2 & 5 & 10 & 15 & 20 & $\begin{array}{c}\text { days } \\
\text { No }\end{array}$ \\
\hline Neutro. & 5.7 & 1.1 & 5.1 & 4.2 & 2.9 & 0.8 \\
Eosino. & 6.2 & 8.0 & 4.8 & 4.6 & 3.1 & 3.8 \\
Mast cells & 0.9 & 2.1 & 1.4 & 0.7 & 0.4 & 1.7 \\
Plasma. & 0.1 & 0 & 0.1 & 0 & 0 & 0 \\
Lympho. & 25.2 & 29.8 & 30.4 & 55.1 & 60.4 & 46.5 \\
Mono. & 61.9 & 59.0 & 53.6 & 35.3 & 33.2 & 47.2 \\
Tumor cells & 0 & 0 & 4.6 & 0.1 & 0 & 0
\end{tabular}

Table VI. Mean Relative Values of Leucocyte Counts in Donryu Rats in which the Tumor Cells Inoculated Had Regressed in the Hetero-and Homo-transplantation

\begin{tabular}{|c|c|c|c|c|c|c|c|c|c|c|c|}
\hline \multirow{4}{*}{ Cell type } & \multicolumn{11}{|c|}{ Days after transplantation } \\
\hline & \multicolumn{2}{|c|}{ (MH $129 \mathrm{~F})$} & \multicolumn{5}{|c|}{ (YS 10 } & \multicolumn{4}{|c|}{ (YS 107) } \\
\hline & days & \multirow[b]{2}{*}{15} & \multicolumn{2}{|c|}{ days } & \multirow[b]{2}{*}{10} & \multirow[b]{2}{*}{15} & \multirow[b]{2}{*}{20} & \multicolumn{2}{|c|}{ days } & \multirow[b]{2}{*}{10} & \multirow[b]{2}{*}{15} \\
\hline & 25 & & 2 & 5 & & & & 2 & 5 & & \\
\hline Neutro. & 4.40 & 0.9 & 3.0 & 0.6 & 0.4 & 0.9 & 0.9 & 0.1 & 0.3 & 1.5 & 0.8 \\
\hline Eosino. & $\begin{array}{ll}7.6 & 3.3\end{array}$ & 2.5 & 5.1 & 4.9 & 3.9 & 2.3 & 3.2 & 1.1 & 1.5 & 1.8 & 1.1 \\
\hline Mast cells & 1.81 .1 & 1.6 & 4.3 & 2.2 & 0.8 & 2.3 & 3.4 & 0.8 & 1.6 & 2.5 & 0.7 \\
\hline Plasma. & 0.10 & 0 & 0 & 0 & 0 & 0 & 0 & 0 & 0.1 & 0.1 & 0 \\
\hline Lympho. & 16.819 .2 & 20.2 & 15.6 & 32.0 & 30.7 & 36.7 & 33.5 & 48.5 & 53.4 & 49.8 & 45.7 \\
\hline Mono. & 51.057 .8 & 74.8 & 72.0 & 60.0 & 64.1 & 57.5 & 59.0 & 31.9 & 43.1 & 44.3 & 51.7 \\
\hline Tumor cells & 18.318 .6 & 0 & 0 & 0.3 & 0 & 0.3 & 0 & 17.6 & 0 & 0 & 0 \\
\hline
\end{tabular}

a) Neutrophils: The relative values of the neutrophils had been increased at the beginning of each inoculation, such as hetero-graft, hetero-homo-graft and homo-graft following B.C.G. treatment, and thereafter kept a constant distribu- 
tion in smear. b) Eosinophils: It had been increased with neutrophils at the beginning of each inoculations such as hetero-graft, hetero-homo-graft and homo-graft following B.C.G. treatment, and gradually kept up a balance. c) Mast cells: In each cases its own distribution was observed. It was difficult to find the regularity in the ascites. d) Plasma cells: In these specimens, there were no specific changes. e) Lymphocytes and monocytic cells: Increase in the relative values of the lymphocyte was prominent in these groups, 1) and 2). This increase was observed even in the ascites where the tumor cells were still existing. Repeated inoculation of homografting showed the high resistance against Yoshida sarcoma and the relative values for lymphocyte had increased step by step.

\section{CONSIDERATION}

It is generally accepted in pathology as a definition of cancer that the malignant cells have the autonomic growth ability. In facts, when a cancer developed in a man, the cancer cells grew and never stopped until the patient would die. However, were the cancer cells always able to grow in any situation where they were placed? Through our experiences in transplantation of ascites tumors such as Yoshida sarcoma, ascites hepatomas and many other tumors, various strange phenomena were sometimes observed, such as the spontaneous regression of tumors, or unusual procedure of tumor growth. Thus for example, there are cases in which the growth of tumor cells is stopped, then they disappear showing degeneration and necrosis in spite of the growth ability which they had, or the tumor-bearing hosts fail to die and survive longer than usual and tumor cells stay in quiet condition. The tumor cells obtained from such tumorbearing hosts, used to give a marked growth again in the new recipients. This means that the tumor cells did not lose their growth ability although they could not display it in that situation. If it is uncovered what is concerned with the inhibition of the growth of tumor cells, it is not only interesting to know the biological behaviour between the tumor cells and the host, but also important step in the approach to the cure of cancer, the target in the research fields of cancer. We have been investigating the relationship between the tumor and the host using experimental transplantable tumors. The tumor cells of Yoshida sarcoma could grow markedly and the host animals used to die with tumor growth when the tumor cells were transplanted into the peritoneal cavity of the nontreated control rats of Donryu strain. In the experiments, the animals were treated through various ways such as the heterografts, the inoculation of the cell suspention of various organs, and the stimulation or blocking of the reticuloendothelial system of the body. When the tumor cells, especially small numbers of them were transplanted in these pretreated animals, the growth was inhibited and many of the animals survived. The results could be interpreted the condi- 
tion of the hosts were changed to the situation in which the tumor cells could hardly grow. In another words, the hosts might have acquired the resistance against the growth of tumor cells. It was assumed that the resistance acquired might have been correlated with the function of the reticulo-endothelial system. In the experiments, however, the grade of the resistance acquired through the stimulation of the RES was not strong enough to inhibit the growth of tumor cells, when large number of them were transplanted, but the tumor growth seemed to be influenced when small numbers of tumor cells were transplanted in the hosts of some groups in which the typhoid vaccine and zymosan were used as the pretreatments.

It may be reasonable to assume that the reticulo-endothelial system may play an important role in the acquisition of the resistance in the hosts against the growth of tumors, although there need further researches to confirm the assumption. The materials which were used in this series of experiments seem to be adequate to observe the procedures of tumor growth precisely. Thus, the tumor-host relationship can be analyzed either biologically or pathologically.

\section{CONCLUSION}

The growth of the Yoshida sarcoma cells was particularly marked and uniform when they were transplanted into the Donryu rats, which have been bred and selected for these 10 years.

These animals died of tumor even when they were inoculated with small numbers of tumor cells such as $10^{3}$ cells. In this series of experiments, it was tried to know whether the hosts (Donryu rats) can be changed into a different condition, in which the tumor cells cannot grow anymore, in another words, whether the body condition which is highly susceptible to the tumor growth, can be changed to be resistant to the growth of tumors.

Various kinds of pretreatments were given to the animals prior to the transplantation of Yoshida sarcoma cells. The acquired resistance against the growth of Yoshida sarcoma cells was clearly demonstrated in the Donryu rats in some groups of the experiments.

1) The most effective one of various kinds of pretreatments was the heterografting. The rats were inoculated with the mouse ascites tumors before they were transplanted with small numbers of Yoshida sarcoma cells. Marked inhibition of tumor growth was observed in the host, showing the longer survival, the lower growth percentage and the increase of the survival rate. This was explained to be the acquired resistance in the hosts against the tumor growth.

2) The acquired resistance was moderately observed in the animals pretreated with injection of the cell suspension of various organs, and B.C.G. vaccine injection.

3) Correlation between the acquired resistance and the function of the 
TABle VII. Mean Survival Days and Survival Rate of Donryu Rats Transplanted with Yoshida Sarcoma following Various Pretreatments

\begin{tabular}{|c|c|c|c|c|c|c|}
\hline Pretreatment & $\begin{array}{c}\text { No. of } \\
\text { cells }\end{array}$ & $\begin{array}{l}\text { No. of } \\
\text { rats }\end{array}$ & $\begin{array}{l}\text { Tumor } \\
\text { death }\end{array}$ & $\begin{array}{l}\text { Regres- } \\
\text { sion }\end{array}$ & $\begin{array}{l}\text { Mean } \\
\text { Surv. } \\
\text { days }\end{array}$ & $\begin{array}{c}\text { Survival } \\
\text { rate }\end{array}$ \\
\hline Typhoid-paratyphoid vaccine & 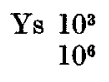 & $\begin{array}{l}10 \\
10\end{array}$ & $\begin{array}{r}9 \\
10\end{array}$ & $\begin{array}{l}1 \\
0\end{array}$ & $\begin{array}{r}12.2 \\
9.6\end{array}$ & $\begin{array}{c}10.0 \\
0\end{array}$ \\
\hline Zymosan & $\begin{array}{r}Y \mathrm{~s} 10^{3} \\
10^{6}\end{array}$ & $\begin{array}{r}9 \\
10\end{array}$ & $\begin{array}{r}6 \\
10\end{array}$ & $\begin{array}{l}3 \\
0\end{array}$ & $\begin{array}{r}11.7 \\
8.8\end{array}$ & $\begin{array}{c}33.3 \\
0\end{array}$ \\
\hline Trypan blue & Ys $\begin{array}{r}10^{3} \\
10^{6}\end{array}$ & $\begin{array}{l}10 \\
10\end{array}$ & $\begin{array}{l}10 \\
10\end{array}$ & $\begin{array}{l}0 \\
0\end{array}$ & $\begin{array}{r}11.9 \\
8.5\end{array}$ & $\begin{array}{l}0 \\
0\end{array}$ \\
\hline Carbon & Ys $10^{3}$ & 10 & 10 & 0 & 11. 7 & 0 \\
\hline Control & $\begin{array}{r}\text { Ys } 10^{3} \\
10^{6}\end{array}$ & $\begin{array}{r}20 \\
8\end{array}$ & $\begin{array}{r}20 \\
8\end{array}$ & $\begin{array}{l}0 \\
0\end{array}$ & $\begin{array}{l}13.3 \\
10.5\end{array}$ & $\begin{array}{l}0 \\
0\end{array}$ \\
\hline B.C.G. vaccine & Ys $\begin{array}{r}10^{3} \\
10^{6}\end{array}$ & $\begin{array}{l}20 \\
20\end{array}$ & $\begin{array}{l}12 \\
19\end{array}$ & $\begin{array}{l}8 \\
1\end{array}$ & $\begin{array}{r}14.6 \\
8.4\end{array}$ & $\begin{array}{r}40.0 \\
5.0\end{array}$ \\
\hline Heterograft & $\begin{array}{r}Y_{\mathbf{B}} 10^{3} \\
10^{6}\end{array}$ & $\begin{array}{l}89 \\
85\end{array}$ & $\begin{array}{l}14 \\
53\end{array}$ & $\begin{array}{l}75 \\
32\end{array}$ & $\begin{array}{l}21.5 \\
10.3\end{array}$ & $\begin{array}{l}84.3 \\
37.6\end{array}$ \\
\hline
\end{tabular}

reticulo-endothelial systems was investigated.

\section{Acknowledgment}

We wish to express our thanks to Dr. T. Watanuki, Assistant Professor of Pathology, Tohoku University, for helpful suggestion, and to Dr. M. Sato and Dr. S. Inooka of our Institute for providing samples of B.C.G. vaccine and zymosan.

\section{References}

1) Sato, H., Tr. Soc. Path. Jap., 1956, 44, 392.

2) Sato, H. \& Satoh, H., Gan-no-Rinshô, 1962, 8, 621.

3) Satoh, H., Tashiro, T., Isaka, H., Fujii, K. \& Sato, H., Proc. Jap. Cancer Ass., 20th General Meeting, 1962. 129.

4) Old, L. J., Ann. N.Y. Acad. Sci., 1960, 88, 264.

5) Old, L. J. \& Clarke, D.A., Nature, 1959, 184, 291.

6) Akazaki, K. \& Kojima, M., The Saishin-Igaku, 1958, 13, 986.

7) Ogima, I. \& Kondo, A., Proc. Jap. Soc. R.E.S., 1962, 2, 28.

8) Fujii, K., Takahashi, T. \& Sato, H., Proc. Jap. Cancer Ass., 21st General Meeting, $1962,221$.

9) Yoshida, T., Jikken Dôbutsu, 1958, 7, 85. 